\title{
Visual Evoked Potentials in the Forebrain of the Pigeon
}

\author{
Denis M. Parker and Juan D. Delius \\ Department of Psychology, Durham (England)
}

Summary. The telencephalon of anaesthetized pigeons was systematically explored for flash evoked potentials. A short latency projection to the hyperstriatum was confirmed. A second short latency projection which appears to have a major focus in the medial sector of the neostriatum caudale and a more diffuse representation in the remainder of this structure was also found. Longer latency responses were found in a band of tissue surrounding the ectostriatum although the latency of these potentials was too short to be compatible with their origin in a projection from the thalamic nucleus rotundus. The core of the ectostriatum was not responsive under the conditions of the present study. A previously reported projection to the avian archistriatum was not confirmed and evidence is presented that supposed evoked potentials in this region of the brain were confused with volume conducted electroretinograms. All forebrain evoked potentials were attenuated by repetition rates above $1 \mathrm{hz}$. The origin of these projections is discussed in conjunction with evoked potentials recorded at lower levels of the pigeon's visual system under the same conditions and in the light of available anatomical and electrophysiological evidence. It is concluded that the information about visual projections to the avian forebrain is as yet too incomplete to be useful as evidence for presumptive avian-mammalian forebrain homologies.

Key words: Visual system — Eroked potentials - Pigeon

\section{Introduction}

The organisation of the forebrain of birds is, at least superficially, quite different from that of mammals. Of particular note is the absence of any clearly differentiated neocortex and the expansion of areas believed to be homologous to the corpus striatum of mammals. While anatomical, developmental and histochemical evidence has made probable the homology of the paleostriatum primitivum, the paleostriatum augmentatum and the hippocampus of birds with respectively, the mammalian globus pallidus, the putamen and the hippocampus, the homologies, if any of the remainder of the avian forebrain masses remain doubtful (Kappers, Huber and Crosby, 1936; Kuhlenbeck, 1938; Stingelin, 1958; Haelfinger, 1958; Jones and Levi-Montalcini, 1958; Kallen, 1962; Fox, Hillman, Siegesmund and Sether, 1966; Baker-Cohen, 1968; Karten, 1969 b). Recent studies of the projection of specific thalamic nuclei to the telencephalon promises further clarification of the organization of the avian forebrain (Powell and Cowan, 1961 ; Karten, 1969a; Revzin and Karten, 1967; Karten and Nauta, 1968). The 
projection of the thalamic visual system is particularly interesting since it has been proposed by Karten (1969 b) that the avian telencephalic visual system may be similarly organized to that of mammals. Thus the visual projection from the subgroups of nucleus dorsolateralis anterior to the hyperstriatum may be homologous to the geniculo-striate system of mammals, while the projection from the optic tectum via the nucleus rotundus to the ectostriatal area of the forebrain may be homologous to the system that ascends from superior colliculus via the nucleus lateralis posterior thalami to the circumstriate cortex of mammals (Karten, 1969 b).

While it would be extremely interesting if the avian forebrain turned out to have a functional organization similar in many respects to that of mammals, only a limited number of pathways have been followed from the thalamus to forebrain. There are reports in the literature of structures within the avian forebrain, other than the ectostriatum and hyperstriatum, which are responsive to visual stimuli. Bremer, Dow and Moruzzi (1939) reported an "on" response to illumination of the contralateral eye when recording from the dorsal cortex of the pigeon. As this response was not abolished by cocainisation of the surface they concluded that the response was subcortical in origin. Phillips (1966) recorded short latency evoked potentials to light flashes in the archistriatum of the chicken. These findings have not been subsequently substantiated and in addition there appear to be large areas of the avian telencephalon that have not been explored for their possible involvement in visual function. In many respects it would be surprising if the visual projection to the forebrain were confined to a restricted area within the hyperstriatum and to the ectostriatum, since the direct projections of the optic tract in the pigeon are quite numerous (Cowan, Adamson and Powell, 1961; Karten and. Nauta, 1968). While the majority of these nuclei have been shown not to degenerate when the forebrain is damaged (Powell and Cowan, 1961) there may of course be sufficient intrathalamic and mesencephalic colaterals to maintain the integrity of their cells.

This report describes the results of a systematic exploration of the pigeon's forebrain for evidence of responsiveness to light flashes.

\section{Methods}

The experiments were performed on 30 adult pigeons (Columba livia). The birds were anaesthetised with $2.5 \mathrm{cc}$ per $\mathrm{kg}$ of intramuscular Equithesin (a mixture of pentobarbital and chloral hydrate; Jensen-Salsberry Labs. USA) and placed in a stereotaxic apparatus equipped with a head holder as specified by Karten and Hodos (1967). The stimulus was a $40 \mathrm{~ns}, 90$ joule flash delivered by a Dawe stroboscope positioned $45 \mathrm{~cm}$ from the birds head. Bipolar recording electrodes were made with $0.2 \mathrm{~mm}$ diameter stainless steel wire inserted into 0.5 outer diameter stainless steel tubing. The conical tip, with concentric active areas, was $0.5 \mathrm{~mm}$ long. For a few experiments monopolar electrodes were made from insulated tungsten wire with an active tip of approximately $0.05 \mathrm{~mm}$ diameter. For one series of recordings (see Fig. 4) semi-micro bipolar electrodes were used, the active areas of the tips being approximately $40 \mu$. The recording was differential and the potentials were amplified on a Tektronix 122 preamplifier with a time constant of 1 sec and a high frequency cut off at 250 cycles. The preamp output was fed into a Biomae 500 transient computer and simultaneously monitored on an oscilloscope. Permanent records were obtained by photographing an oscilloscope display of the averaged potentials. Recordings were taken at $1 \mathrm{~mm}$, sometimes $0.5 \mathrm{~mm}$ intervals, along each electrode track. The averaged responses were derived from 32 stimulus presentations at a rate of 1 flash per second unless otherwise stated. Usually 2 averages were taken at each point, one with a sweep duration of $62.5 \mathrm{msec}$ and another with a duration of $250 \mathrm{msec}$. The shorter 


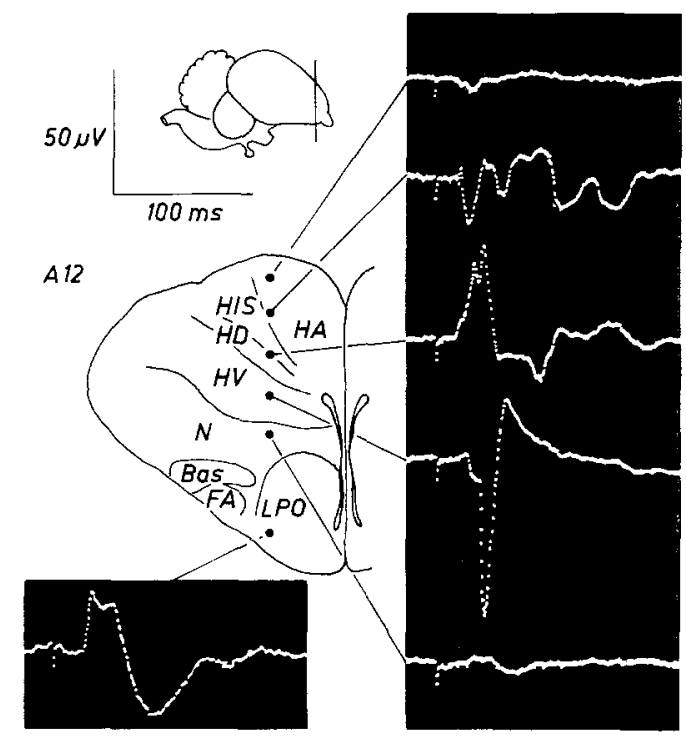

Fig. I. Flash evoked potentials from hyperstriatum. The electroretinogram (left) was recorded about $1 \mathrm{~mm}$ more anteriorly on a different electrode track and arose by ocular transillumination. Abbreviations: Bas nucleus basalis, FA tractus fronto-archistriaticus, HA hyperstriatum accessorium, HD hyperstriatum dorsale, HIS hyperstriatum intercalatus superior, HV hyperstriatum ventrale, $\mathrm{N}$ neostriatum, LPO lobus parolfactorius. Downward deflection: tip positive with respect to sheath

sweep duration enabled accurate estimates of the latencies of the potentials to be made. Latencies were measured from the stimulus marker to the inflection voint of the first departure from baseline except where otherwise stated. If any doubt arose as to the reliability of a given potential i.e. if the build up of amplitude was not systematic, then the averaging process was repeated. The electrode tip position was marked with a small radiofrequency lesion at the bottom of each track or when a site yielded an interesting response. The formalin perfused brains were processed with conventional histological techniques. Electrode tracks were marked on drawings of transverse sections of the pigeons brain and related to the corresponding recordings.

\section{Results}

70 tracks evenly distributed over the hemisphere contralateral to the stimulated eye were explored.

In the frontal forebrain, evoked potentials were reliably obtained throughout the hyperstriatal region. In general these potentials were of small amplitude, $10-20 \mu \mathrm{v}$, but in a restricted region of the anterior hyperstriatum (between A 10.5 and A 12 of the sterotaxic atlas of Karten and Hodos, 1967) large potentials of $40-100 \mu \mathrm{v}$ were obtained (Fig. 1). Two major features were noted during penetrations through this region of the brain. The first was the double reversal of the potential as the electrode was advanced ventralward. The first peak of the potential which appeared when the electrode tip approached the border of the hyperstriatum intercalatus superior was positive with respect to the sheath. When the tip passed out of the hyperstriatum intercalatus superior and into the hyperstriatum dorsale the potential reverses. A second reversal occurs when the tip 




Fig. 2. Flash evoled potentials from the neostriatum intermedium surrounding the ectostriatum. Abbreviation as in Fig. 1 and E ectostriatum, NI neostriatum intermedium, PA paleostriatum augmentatum, PP paleostriatum primitivum, TSM tractus septo-mesencephalicus. Polarity as in Fig. 1



Fig. 3. Flash evoked potentials from the paleostriatum. Abbreviations as in the previous figures and CA commissura anterior, CO chiasma opticum, FPL fasciculus prosencephali lateralis, Hp hippocampus. Polarity as in Fig. I

enters the hyperstriatum ventrale. The second noticeable feature is the complexity of the potential at the border of the hyperstriatum intercalatus superior and the way in which the waveform becomes simpler as the electrode is advanced ventralward. The latency of the hyperstriatal potentials was between 21 and $23 \mathrm{msec}$. 


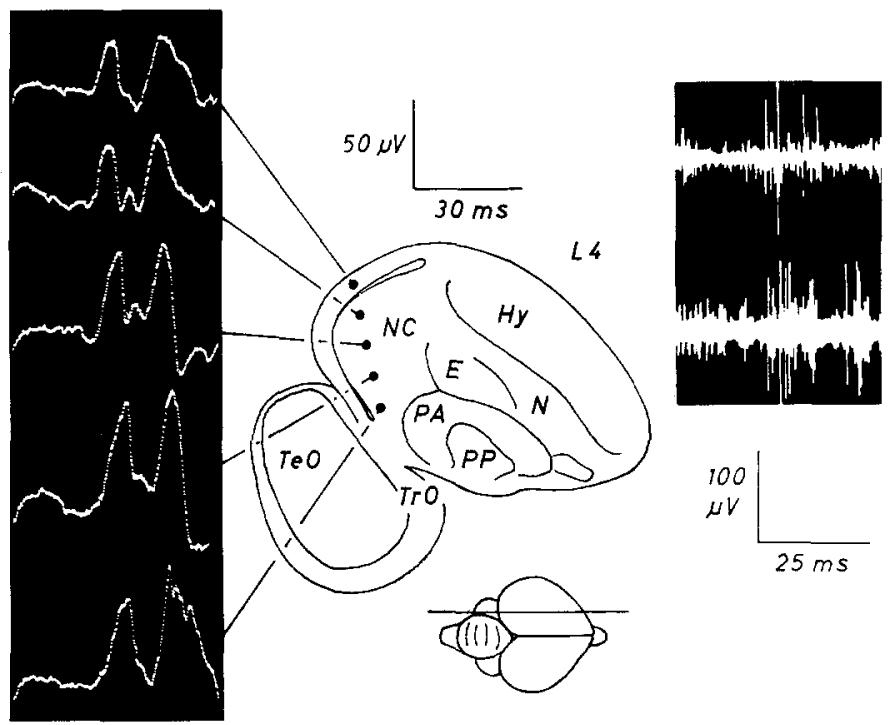

Fig. 4. Flash evoked potentials from the neostriatum caudale. Monopolar recordings. Insert (right) illustrates unit clusters recorded in the same region using semi micro bipolar electrodes (tip $40 \mu$ ) and a band pass filter (passing 400-1200 hz). Abbreviations as in previous figures and Hy hyperstriatum, NC neostriatum caudale, $\mathrm{TeO}$ tectum opticum, $\mathrm{TrO}$ tractus opticum.

Upward deflection indicates tip positive

Flash evoked potentials were also recorded from a region constituted by parts of the neostriatum intermedium and the lateral neostriatum immediately surrounding the ectostriatum anteriorly, medially, dorsally, laterally and posteriorly (Fig. 2). When, for example, the ectostriatum was approached from above, a large amplitude potential of $100-150 \mu \mathrm{v}$ was recorded as soon as the electrode tip entered the neostriatum. The potential reversed its polarity as the tip entered the ectostriatum and disappeared completely when the sheath of the bipolar electrode entered this structure. The latency of these potentials was between 35 and 40 msec.

No potentials could be recorded from anywhere in the core of the ectostriatum even though the nucleus rotundus in the thalamus, which is the origin of the ectostriatal afferents, yielded a large response ( $500 \mu \mathrm{v}, 52 \mathrm{msec}$ latency) under the same experimental conditions in which the ectostriatum was silent. The evoked potential recorded within the nucleus rotundus follows the response recorded in the stratum griseum centrale of the optic tectum, the main input to this nucleus (Revzin and Karten, 1967), by a few msec (see also Fig. 8). The evoked potentials found in that region of the neostriatum surrounding the ectostriatum precede the responses found in the output layer of the optic tectum and the nucleus rotundus by $10-15$ msec.

Evoked responses of between 80 and $200 \mu \mathrm{v}$ amplitude could be recorded from the full extent of the paleostriatum augmentatum (Fig. 2 and Fig. 3). The paleostriatum primitivum however appeared to be essentially non-responsive. The latency of the evoked potentials found in the paleostriatum augmentatum was between 33 and $35 \mathrm{msec}$. 


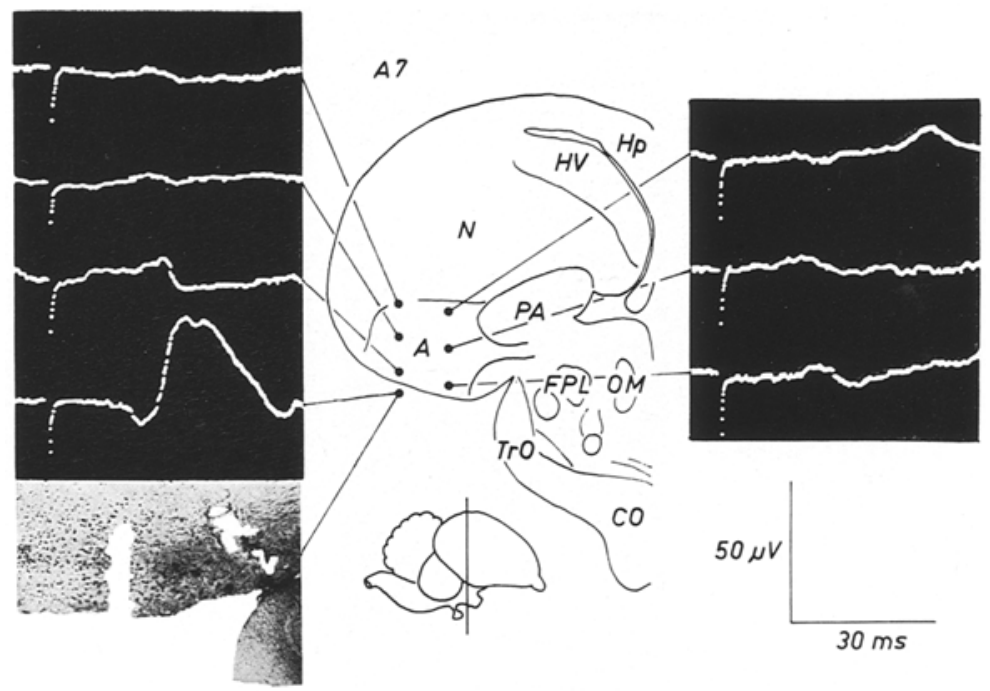

Fig. 5. Absence of flash evoked potentials in the archistriatum. The photomicrograph (left) documents the origin of the electroretinogram. Abbreviations as in previous figures and $A$ archistriatum, OM tractus occipito-mesencephalicus. Polarity as in Fig. 1

Another region of the forebrain that yielded visually evoked responses was the neostriatum caudale. The potentials from this region are easily picked up when recording in the monopolar mode (Fig. 4). When recording in a bipolar mode, potentials are only recorded from a restricted region in the medial part of the neostriatum caudale (Fig. 7). It seems unwise to conclude however that the potentials recorded with monopolar electrodes are simply current spread from a localized generator in the medial part of the neostriatum caudale as unit clusters, firing with the appropriate latency, may be found outside this restricted area (see insert Fig. 4). The latency of these potentials is between 21 and 23 msec.

For some time it appeared that several ventrally located regions within the forebrain, including the archistriatum, produced short latency evoked potentials to visual stimulation thus confirming the results of Phillips (1966). Closer analysis however revealed that these structures are unresponsive and that the potentials were artefacts. The earliest potentials that were recorded in the optic tract had a latency of $15 \mathrm{msec}$ while these potentials had latencies of $12-15 \mathrm{msec}$. It soon became clear that these potentials were electroretinograms generated ipsilateral to the site recorded from (Fig. 5). They could be observed, though smaller, even when the eye ipsilateral to the recording electrode was carefully shielded from the glare of the flash. Light presumably reached its retina by transillumination through the other eye since in pigeons the eyes are closely apposed medially (Chard and Gundlach, 1938; Wolbarsht et al., 1964). While in most cases the appearance of the electroretinogram was a certain sign that the electrode had touched the bony lamina separating the cranial cavity from the eye socket, in the lobus paraolfactorius, below which the bone is perforated by a foramen, a sizeable volume conducted E.R.G. of up to $120 \mu \mathrm{v}$ could be recorded well within the neural tissuẹ 




Fig. 6. Attenuation of forebrain flash evoked potentials with increasing stimulus frequency. Records from the hyperstriatum ventrale of the pigeon

(Fig. 1). When recording in the monopolar mode the E.R.G. was often an artefact pervading recordings from elsewhere in the brain.

A general feature of all forebrain flash evoked potentials was that they were all strongly attenuated by stimulus repetition rates above $0.5-1 \mathrm{hz}$ (Fig. 6). This was not only due to a refractory period type phenomenon but also to a habituation like process, since after a prolonged pause in stimulation the amplitude of the evoked potential would only decrease to the typical for that frequency level after several flashes of the series. Such marked stimulus frequency dependant attenuation was not detected for any of the diencephalic or mesencephalic visually evoked potentials recorded during this study.

\section{Discussion}

The major visual projections to the pigeon forebrain have been summarized by Karten $(1969 \mathrm{~b})$. One projection ascends from the optic tectum via the thalamic nucleus rotundus to the ectostriatum (see Fig. 7). From the ectostriatum there is evidence of a projection to the dorsolateral surface of the hemisphere and to the neostriatum intermedium. Another projection ascends from the dorsolateral anterior thalamic complex of the pigeon brain, via the lateral forebrain bundle to the hyperstriatum dorsale and the hyperstriatum accessorium (Fig. 7). In addition to these 


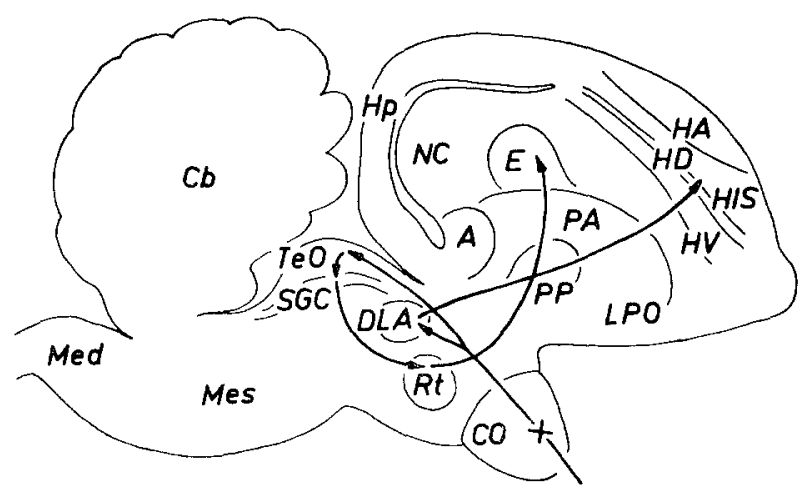

Fig. 7. Visual projections to the avian forebrain. Schematic diagram showing the relative positions of visual system structures in the avian brain (sagittal section). A archistriatum, CB cerebellum, CO optic chiasma, DLA dorsolateral anterior thalamic complex, E ectostriatum, HA hyperstriatum accessorium, HD hyperstriatum dorsale, HIS hyperstriatum intercalatus superior, HP hippocampus, HV hyperstriatum ventrale, LPO lobus parolfactorius, Med medulla, Mes mesencephalon, NC neostriatum caudale, NI neostriatum intermedium, PA paleostriatum augmentatum, PP paleostriatum primitivum, Rt nucleus rotundus, SGC stratum griseum centrale, TeO tectum opticum. The cross denotes a total decussation

major projections there have been two reports of visual projection to other parts of the avian telencephalon. Bremer, Dow and Moruzzi (1939) reported evoked potentials to visual stimuli in the caudal part of the pigeons hemisphere, and Phillips (1966) reported visual evoked potentials in the archistriatum of the chicken forebrain, although the anatomical projections to these areas were not indicated. The relative position of these areas within the pigeon hemispheres is indicated diagrammatically in Fig. 7.

A summary of the flash evoked responses obtained is presented in Fig. 8. The latency figures quoted in the following discussion are accurate since repeated penetration of the same structure under similar conditions yielded identical latencies. This is to be expected since the latency data were measured from the photographs of averaged potentials. There is also good agreement with the results of previous authors regarding the latencies found at various points in the pigeon's visual system when visual stimulation is used. Thus Rougeul (1957) indicated a latency of approximately $20 \mathrm{~ms}$ for the evoked potential in the hyperstriatum (compared to our 21-23 ms); Revzin (1966) indicates a latency of $60 \mathrm{~ms}$ for units in the nucleus rotundus (our results indicate $52 \mathrm{~ms}$ ); Hamdi and Whiteridge (1954) indicate a latency of $50 \mathrm{msec}$ for the response of the central tectum (our results indicate $48-50 \mathrm{~ms}$ ); Galifret (1966) indicates a latency of $17 \mathrm{~ms}$ for the evoked potential recorded in the superficial optic tectum (compared to our $17-18 \mathrm{~ms}$ ). We are thus confident that latency comparisons are meaningful.

The evoked potentials found in the hyperstriatum present little difficulty in interpretation. They correspond to those obtained by Adamo and King (1967) and by Rougeul (1957) as regards site and latency. It is probable that these potentials reflect the projection from the dorsal thalamus to the wulst described by Karten and Nauta (1968) and Revzin (1969). The surprising feature of the evoked potentials reported here is the complexity of the response in the superior part of the hyper- 


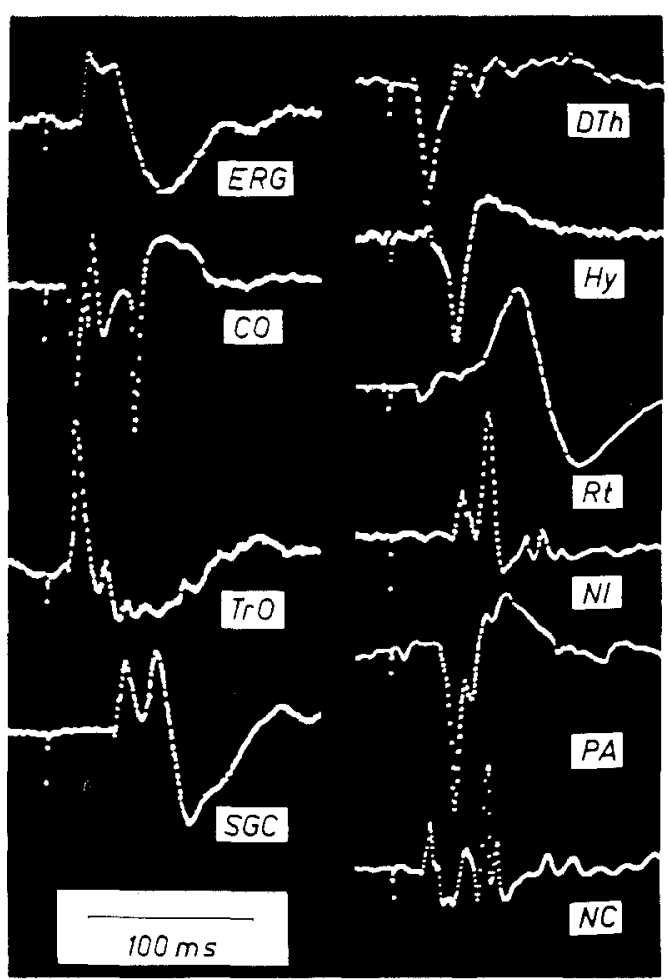

Fig. 8. Flash evoked potentials from various visual system structures. The initial downward deflection of the potential recorded from the nucleus rotundus is due to the tip being located ventral to the nucleus rotundus and overlying the lateral geniculate nucleus pars ventralis (see text). Abbreviations: CO chiasma opticum, Dth nuclei dorsalis thalami, ERG electroretinogram, Hy hyperstriatum, NI neostriatum intermedium, NC neostriatum caudale, PA paleostriatum augmentatum, Rt nucleus rotundus, SGC stratum griseum centrale, TrO tractus opticum. The electroretinogram arose by ocular transillumination (see text) with a consequent increased latency due to the reduction in illumination. Its latency is therefore not strictly comparable with that of the other potentials (see Crampton and Boggs, 1959)

striatum (close to the border of the hyperstriatum intercalatus superior) and the way in which the waveform becomes simpler as the electrode proceeds ventralward. This suggests that there may be successive projections of visual fibres within the hyperstriatum, as the latency of the initial peak is similar regardless of depth while the number of peaks increases as the electrode nears the surface of the brain. The double reversal of the initial peaks of the potentials recorded during penetration of this region appears to offer further support for the view that there is more than one layer of termination within the hyperstriatum of the pigeon. In the burrowing owl the projection from dorsal thalamus terminates in both the hyperstriatum dorsale and the ventral margin of the hyperstriatum accessorium (Karten, 1969 b). In the pigeon the termination of visual fibres within the hyperstriatum may be at least as complex as this. It should be noted however that our work does not indicate that the projection to the hyperstriatum is confined to a restricted area in the anterior region of this structure. While the evoked potentials 
found outside this restricted area are smaller in amplitude that those found within it, there is no evidence that the smaller amplitude potentials found in the most anterior and posterior (Fig. 3). areas of the hyperstriatum can be attributed to current spread from a restricted area. The fact that the recording was differential and the electrodes were concentric bipolars minimized any current spread that might have occurred. This is supported by the fact that potentials appeared, reversed and disappeared abruptly as the electrode was advanced through the brain during the present investigations. The only exception to this was the E.R.G. recorded within the lobus paraolfactorius (Fig. 1), and the fact that an E.R.G. could be recorded within the brain in this area is rather puzzling, although it is probably connected with the fact that there is a foramen in the eye socket just below the area from which this response was recorded and the brain is not so well insulated from the eye at this point. From the evidence of this study it would appear that the visual projection to the hyperstriatum terminates mainly in a fairly restricted area but that this is surrounded by a more diffuse projection.

In some ways the failure to find evoked potentials within the ectostriatum was surprising. There can be no doubt that a massive projection from the thalamic nucleus rotundus goes to the ectostriatum (Kondo, 1933*; Revzin and Karten, 1967; Karten and Hodos, 1970). However the answer to this failure may lie in the fact that Revzin $(1969,1970)$ and Kimberly, Holden and Bamborough (1971) have reported that units in the pigeons ectostriatum are sensitive to movement and the majority possess wide fields. The diffuse flash used in the present study was probably an inappropriate stimulus, although a clear response was found in the nucleus rotundus under the same conditions. The envelope of tissue that surrounds the ectostriatum and which yields large amplitude evoked potentials is however extremely interesting. This area may correspond to what Karten (1969 b) calls the periectostriatal belt. Since the evoked potentials found in this region have too short a latency to be relayed via the tecto-rotundal pathway and must originate through another system, the convergence of visual information from two divisions of the visual system on neighbouring parts of the telencephalon suggests what may be an important functional link up. Karten $(1969 \mathrm{~b})$ has reported that in the burrowing owl there is a projection from hyperstriatum to the periectostriatal belt. If such a pathway exists in the pigeon then it may well carry the fibres that give rise to the evoked potentials found in the present study. Another possibility is that the evoked potentials found in the paleostriatum augmentatum represent the activity of fibres of passage which project to the ectostriatal surround. The latency of these potentials is appropriate for such an interpretation $(33-35 \mathrm{~ms})$. On the other hand no potentials were found in the paleostriatum primitivum, a structure which is also traversed by afferent tracts to the forebrain (Kappers et al., 1936), a fact which may suggest that there is a projection to the paleostriatum proper.

The evoked potentials found in the neostriatum caudale are interesting because they confirm that a visual projection does terminate in this region of the pigeons forebrain (Bremer, Dow and Moruzzi, 1939). When recording with bipolar electrodes evoked potentials are only found in a restricted area of the neostriatum

* It is perhaps opportune to call attention here to a fine series of papers by Kondo (1933a, $1933 \mathrm{~b}, 1933 \mathrm{c}$ ) on avian forebrain connections which seem not to have been hitherto noticed. 
caudale just posterior and lateral to Karten's area L (Karten, 1969). Recording with monopolar electrodes, responses are widely distributed over the neostriatum caudale. That these responses are not just spread from a localized generator within the medial sector of the neostriatum caudale is shown by the fact that unit clusters that fire to visual stimuli with the appropriate latency can be recorded throughout the neostriatum caudale. It appears probable that the visual projection to this area of the pigeon's forebrain is organized in a similar way to the visual projection to the hyperstriatum, in that it involves a dense projection to a fairly localized region and a more diffuse projection to the remainder of the area.

The absence of visually evoked potentials in the archistriatum of pigeons is contrary to the finding of Phillips (1966) in chickens. Since however the latencies he indicates for the responses he recorded correspond with the latencies that Crampton and Boggs (1959) indicate for the chicken electroretinogram, it seems likely that the former are artefacts resulting from electrode contact with the eye socket, although the possibility cannot be definitely excluded that differences in the anaesthetics used may account for the difference in results.

Briefly then this study confirms a visual projection to the hyperstriatum but suggest that it may be distributed over a wider area than previously thought (Karten and Nauta, 1968; Revzin, 1969), shows that a belt of tissue surrounding the ectostriatum receives a sizeable visual projection, confirms that the neostriatum caudale receives a short latency visual projection and finally shows that visual evoked potentials are not found within the archistriatum. An interpretation of these results in terms of avian - mammalian homologies would be premature without data on anatomical correlates and the functional characteristics for most of these areas.

It remains to comment on the stimulus frequency dependant attenuation we found to affect all visually evoked forebrain potentials. In fact this appears to be a general characteristic for all avian forebrain evoked responses: Harman and Phillips (1967) reports it for auditory potentials and it also affects telencephalic somatosensory evoked responses (Delius and Bennetto, in press). The functional significance as well as the mechanism responsible for it are as yet obscure.

\section{References}

Adamo, N.J., King, R.L.: Evoked responses in the chicken telencephalon to auditory visual and tactile stimulation. Exp. Neurol. 17, 498-504 (1967).

Baker-Cohen, K.F.: Comparative enzyme-histochemical observations on sub-mammalian brains. Ergebn. Anat. Entwickl.-Gesch. 40, 1-70 (1968).

Bremer, F., Dow, R.S., Moruzzi, G.: Physiological analysis of the general cortex in reptiles and birds. J. Neurophysiol. 2, 473-499 (1939).

Chard, R., Gundlach, R.H.: The structure of the eye in the homing pigeon. J. comp. Psychol. 25, 249-272 (1938).

Cowan, W.M., Adamson, L., Powell, T.P.S.: An experimental study of the avian visual system. J. Anat. (Lond.) 95, 545-563 (1961).

Crampton, G.H., Boggs, N.: Latencies of the E.R.G. and optic tectum evoked potentials in the chicken. Amer. J. Physiol. 196, 1067-1075 (1959).

Delius, J.D., Bennetto, K.: Cutaneous sensory projections in the avian forebrain and thalamus. Brain Res. (in press) (1972).

Fox, C.A., Hillman, D.E., Siegesmund, K.A., Sether, L.A.: The primate globus pallidus and its feline and avian homologue: a golgi and electron microscopic study. In: R. Hassler and H. Stephan, Evolution of the Forebrain. Stuttgart: Georg Thieme 1966. 
Galifret, Y.: Le systeme visuelle du pigeon. Ph. D. thesis, Université de Paris, 1966.

Haefelfinger, H.R.: Beiträge zur vergleichenden Ontogenese des Vorderhirns bei Vögeln. Basel: Helbing and Lichtenhahn 1958.

Hamdi, F.A., Whiteridge, D.: The representation of the retina on the optic tectum of the pigeon. Quart. J. exp. Physiol. 39, 111-119 (1954).

Harman, L.A., Phillips, R.E.: Responses in the avian midbrain thalamus and forebrain evoked by click stimuli. Exp. Neurol. 18, $276-286$ (1967).

Jones, A.W., Levi-Montalcini, R.: Patterns of differentiation of the nerve centres and fibre tracts in the avian cerebral hemispheres. Arch. ital. Biol. 96, 23I-284 (1958).

Kallen, B.: Embryogenesis of brain nuclei in the chick telencephalon. Ergebn. Anat. Entwickl.-Gesch. 36, 62-82 (1962).

Kappers, C.U.A., Huber, G.C., Crosby, E.C.: The comparative anatomy of the nervous system of vertebrates. New York: Macmillan 1936.

Karten, H.J. The ascending auditory pathways in the pigeon. Telencephalic projections of the nucleus ovoidalis thalami. Brain. Res. 11, 134-153 (1969a).

- The organization of the avian telencephalon and some speculations on the phylogeny of the arnniote telencephalon. Ann. N.Y. Acad. Sci. 167, 164-179 (1969b).

- Hodos, W.: A Stereotaxic Atlas of the Brain of the Pigeon (Columbia livia). Baltimore: Johns Hopkins 1967.

- - Telencephalic projections of the nucleus rotundus in the pigeon (Columba livia). J. comp. Neurol. 140, 35-52 (1970).

- Nauta, W.J.H.: Organisation of retinothalamic projections in the pigeon and owl. Anat. Rec. 160, 373 (1968).

- Revzin, A. M.: The afferent connections of the nucleus rotundus in the pigeon. Brain Res. 2, 368-377 (1966).

Kimberly, R.P., Holden, A.L., Bamborough, P.: Response characteristies of pigeon forebrain cells to visual stimulation. Vision Res. 11, $475-478$ (1971).

Kondo, T.: Úber die Nervenfasern, die beim Huhn aus dem Epistriatum entspringen oder in ihm endigen. Okayama I.Z. 45, 124-132 (1933a).

- Über die zentrifugalen Fasern, die beim Huhn aus der vorderen Gegend der Großhirnhemisphäre entspringen. Okayama I.Z. 45, 133-143 (1933 b).

- U̇ber das Mesostriatum beim Huhn. Okayama I.Z. 45, 785-796 (1933 c).

— Úber die Verbindung des Sehhügels mit dem Streifenhügel beim Huhn. Okayama I.Z. 45, $797-809$ (1933d).

Kuhlenbeck, H.: The ontogenetic development and phylogenetic significance of the cortex telencephali in the chick. J. comp. Neurol. 69, 273-295 (1938).

Phillips, R.E.: Evoked potential study of connections of avian archistriatum and caudal neostriatum. J. comp. Neurol. 127, 89-99 (1966).

Powell, T.P.S., Cowan, W.M. : The thalamic projection upon the telencephalon in the pigeon (Columbia livia) J. Anat. (Lond.) 95, 78-109 (1961).

Revzin, A.M. : Flash evoked unit responses in the diencephalon of the pigeon. Fed. Proc. 25, $1163(1966)$.

- A specific visual projection area in the hyperstriatum of the pigeon (Columba livia). Brain Res. 15, 246-249 (1969).

- Some characteristics of wide-field units in the brain of the pigeon. Brain Behav. Evol. 3, 195-204 (1970).

- Karten, H.J.: Rostral projections of the optic tectum and the nucleus rotundus in the pigeon. Brain Res. 3, 264-276 (1967).

Rougeul, A.: Exploration oscillographique de la voie visuelle du pigeon. Paris: Foulon 1957.

Stingelin, W.: Vergleichende morphologische Untersuchungen am Vorderhirn der Vögel auf cytologischer und cytoarchitektonischer Grundlage. Basel: Helbing and Lichtenhahn 1958.

Wolbarsht, M.J., Stopp, P.E., Godson, J.E.: Opthalmoscopy of pigeons using transillumination. Experientia (Basel) 20, 466 (1964).

Dr. D.M. Parker

Department of Psychology

South Road, Durham (England) 